\title{
CARACTERIZAÇÃO ESTRUTURAL DOS AQÜÍFEROS FRATURADOS DA FORMAÇÃO SERRA GERAL NA REGIÃO NORDESTE DO ESTADO DO RIO GRANDE DO SUL
}

\author{
PEDRO ANTÔNIO ROEHE REGINATO ${ }^{1}$ \& ADELIR JOSÉ STRIEDER ${ }^{2}$
}

\begin{abstract}
The fractured aquifers from the Serra Geral Formation play a major role in the Northeastern region of the State of Rio Grande do Sul since they are sources of hydric resources used for public supplying, industrial and agricultural activities. Such fractured aquifers are located in the volcanic sequence of the Serra Geral Formation and are subjected to structural systems. The main identified structures in the region correspond to type 2 lineaments characterized by fractures and fracture zones. These structures are due to the action of two orthogonal tension fields (east-west and north-south) which had effect on the whole region. As a result, extension structures were created (parallel and sub-parallel to the strain axes) which are usually filled up; and hybrid and shear structures (slanting structures between strain and traction axes) which may or may not present filling. Data integration showed that there is a strong correlation between lineaments and productive tubular wells, the northeastern structures (correlations with an outflow between 10 to $20 \mathrm{~m}^{3 / 1}$ ) and the northwestern structures (relations with outflows above $20 \mathrm{~m}^{3 / 1}$ ) being the main ones. The analysis of the orientations for each group of lineaments with productive tubular wells showed that for Northwestern structures the main direction is N30-60W, for Northeastern it is N20-30E, for North-South it is N00-14E and for East-West it is $\mathrm{N} 80-90 \mathrm{~W}$. In relation to the unproductive tubular wells it was observed that the higher occurrence is associated to the Northeastern structures group, whose main orientations are $\mathrm{N} 30-40 \mathrm{E}$ and $\mathrm{N} 50-60 \mathrm{E}$. The result of the structural characterization and its relation with fractured aquifers demonstrates the need for structural analysis (lineaments identification and field surveys) when prospecting fractured aquifers.
\end{abstract}

Keywords: fractured aquifers, lineaments, Serra Geral Formation

\begin{abstract}
Resumo Os aqüíferos fraturados da Formação Serra Geral têm grande importância na região nordeste o estado do Rio Grande do Sul, pois se constituem em fontes de recursos hídricos utilizados para o abastecimento público, desenvolvimento de atividades industriais e agropecuárias. Esses aqüíferos fraturados estão localizados na seqüência vulcânica da Formação Serra Geral, sendo condicionados pelo sistema estrutural. As principais estruturas identificadas na região correspondem a lineamentos do tipo 2 caracterizados por fraturas e zonas de fraturas. Essas estruturas resultaram da ação de dois campos tensionais (um leste-oeste e outro norte-sul) ortogonais que atuaram em toda a região. Como resultado foram geradas estruturas trativas (paralelas e sub-paralelas aos eixos de compressão) que em geral estão preenchidas e estruturas híbridas e de cisalhamento (oblíquas entre os eixos de compressão e tração) que podem ou não apresentar preenchimento. A integração de dados mostrou uma forte correlação entre lineamentos e poços tubulares produtivos, sendo que as estruturas nordeste (correlações com vazões entre $10 \mathrm{a} 20 \mathrm{~m}^{3 / \mathrm{h}}$ ) e noroeste (relações com vazões acima de $20 \mathrm{~m}^{3 / 1}$ ) são as principais. A análise das orientações de cada grupo de lineamentos com poços tubulares produtivos mostrou que para as estruturas noroeste a direção principal é N30-60W, para as nordeste é N20 -30E, para as norte-sul é N00 $-14 \mathrm{E}$ e para as leste-oeste é N80-90W. Com relação a poços tubulares nulos, observou-se que a maior ocorrência está relacionada ao grupo de estruturas nordeste, cujas orientações principais são N30-40E e N50-60E. O resultado da caracterização estrutural e sua relação com aqüíferos fraturados demonstrou a necessidade da análise estrutural (identificação de lineamentos e levantamentos de campo) quando da prospeç̧ão de aqüiferos fraturados.
\end{abstract}

Palavras-Chave: aquíferos fraturados, lineamentos, Formação Serra Geral

INTRODUÇ̃̃o Os aqüíferos da Formação Serra Geral possuem grande importância, pois constituem-se em fontes de recursos hídricos utilizados no desenvolvimento de diferentes atividades. Nessa formação geológica os aqüifferos existentes são denominados de livres ou freáticos e fraturados (Reginato, 2003; Reginato \& Strieder, 2004). O aqüífero livre está localizado no manto de alteração existente sobre as rochas vulcânicas e possui como principais condicionantes os seguintes fatores: solo (tipo e espessura), relevo, litologia (tipo e estruturação primária) e clima. As águas subterrâneas desse aqüiffero são captadas por meio de poços escavados (poços cacimba) ou através de fontes (bastante comuns na região em função da topografia). Essas águas são utilizadas para abastecimento público, doméstico e no desenvolvimento de atividades agropecuárias, nas zonas rurais. $\mathrm{O}$ aqüífero fraturado está localizado nas rochas vulcânicas sendo seu principal condicionante as estruturas tectônicas. Os condicionantes secundários consistem na estruturação primária da rocha, no relevo e no solo (tipo e espessura). Esse aqüífero é caracterizado por uma forte anisotropia, responsável por vazões variáveis e por capacidades específicas, em geral baixas. A forma de captação das águas subterrâneas ocorre por meio de poços tubulares.Na região nordeste do estado do Rio Grande do Sul o aquífero fraturado possui grande importância, pois a maior parte dos poços perfurados é utilizada para abastecimento público (urbano e rural), seguido pelas indústrias (os municípios de Caxias do Sul, Bento Gonçalves, Flores da Cunha e Farroupilha corres-pondem às regiões que mais utilizam esse recurso), pelo setor doméstico (abastecimento de famílias rurais), pelo setor agrícola e pelo ramo de recreação. Além disso, muitos municípios como Monte Belo do Sul, Nova Pádua, Nova Roma, Flores da Cunha e Antônio Prado são abastecidos exclusivamente por água subterrânea (Reginato, 2003; Reginato \& Strieder, 2004).

Nessa região a ocorrência do aquífero fraturado está associada a estruturas tectônicas (fraturas e zonas de fraturas), sendo

1 - Universidade de Caxias do Sul (UCS) / Centro de Ciências Biológicas e da Saúde (CCBS) - Departamento de Ciências Biológicas (DCBI) - Setor de Geociências

(MUCS) Rua Francisco Getúlio Vargas, 1130 - Caxias do Sul/RS - CEP 95.070-560 - Tel. (54) 32182100 e-mail: parregin@ucs.br2

2 - Universidade Federal do Rio Grande do Sul (UFRGS)-Escola de Engenharia (EE) - Departamento de Engenharia de Minas (DEMIN) - Av. Osvaldo Aranha, 99 Sala 502B

- Porto Alegre/RS - CEP 90.035-190-adelir@ufrgs.br 
esse o principal fator geológico adotado nos estudos de prospecção. Assim, em função da importância desses aqüíferos para o desenvolvimento econômico e social da região, e com base nas características hidrogeológicas desse sistema foi desenvolvido este trabalho. O objetivo principal foi o de promover a caracterização estrutural dos aqüíferos fraturados visando auxiliar os processos de prospecção. A caracterização foi realizada com base na análise geométrica, cinemática e dinâmica de estruturas geológicas identificadas em levantamentos de campo e por meio da análise estrutural de lineamentos obtidos de fotografias aéreas. A relação entre o padrão estrutural e os aqüiferos fraturados foi determinada pela integração de dados estruturais e hidrogeológicos através do emprego de técnicas de Geoprocessamento (programa SPRING).

LOCALIZAÇÃO DA ÁREA DE ESTUDO A área abrangida nesse trabalho está localizada na região nordeste do Rio Grande do Sul, compreende parte da Bacia Hidrográfica Taquari-Antas e envolve a área de onze municípios (Veranópolis, Cotiporã, Bento Gonçalves, Farroupilha, Caxias do Sul, Flores da Cunha, São Marcos, Nova Pádua, Nova Roma do Sul, Monte Belo do Sul e Antônio Prado - Figura 1).

CARACTERIZAÇÃo GEOLÓGICA A área de estudo situa-se na porção sul da Bacia do Paraná, a qual constitui uma bacia intracratônica que ocupa aproximadamente 1.200 .000 $\mathrm{km}^{2}$ no Brasil. Essa bacia é caracterizada por uma seqüência sedimentar e uma vulcânica, governadas por um forte controle estrutural (falhas N-NE, N-NO e E-O; Zalan et al., 1990). Os principais litotipos de interesse são rochas vulcânicas da Formação Serra Geral (White, 1908).

No Rio Grande do Sul, a Formação Serra Geral ocupa uma área de $137.000 \mathrm{~km}^{2}$, que equivale a aproximadamente $50 \%$ da área do Estado (Hausman, 1995). É caracterizada por uma seqüência vulcânica básica e ácida, onde os principais litotipos são basaltos toleíticos, andesitos, riodacitos, riolitos e dacitos (Radam/Brasil, 1986; Roisenberg, 1990). A região de estudo foi condicionada por um forte controle tectônico marcado por falhas e fraturas com direções preferênciais N70 - 75E, N35 - 40E e N20 - 30W (Magna, 1997). Esse controle também é observado pela disposição da rede de drenagem, encaixada nos principais lineamentos estruturais e que, conseqüentemente, define um padrão característico de quebras bruscas para os cursos fluviais (exemplo: Rio das Antas).

Conforme levantamento realizado pela CPRM (1998), ocorrem dois litotipos na área de estudo: basaltos do tipo Gramado e vulcânicas ácidas do tipo Palmas/Caxias.

Segundo Reginato (2003) a região é caracterizada por nove derrames principais. Os basaltos constituem seis derrames principais, cujas estruturas primárias consistem de zonas maciças, de disjunção vertical e zonas vesiculares a amigdalóides intercaladas por brechas vulcânicas. As rochas ácidas são riodacitos, dacitos, riolitos e vidro vulcânico e formam três derrames principais onde a estrutura primária é marcada por zonas basais (maciças), de disjunção horizontal, zonas vesiculares a amigdalóides e de brechas vulcânicas.

CARACTERIZAÇÃO HIDROGEOLÓGICA Com relação ao Estado do Rio Grande do Sul, a área de estudo está inserida na província hidrogeológica denominada de "Província Basáltica" (Hausman, 1995).

Conforme Lisboa $(1993,1996)$ a área está inserida na unidade morfotectônica denominada de Fachada Atlântica e nas unidades hidrogeológicas denominadas de Ácidas Aplainadas e Ácidas Dissecadas. A primeira unidade é caracterizada por vulcânicas ácidas associadas a um relevo pouco dissecado e a um manto de alteração de espessura média ( 5 a $10 \mathrm{~m}$ ). Os lineamentos são de médio a pequeno porte com orientação preferencial para nordeste. Essa unidade possui um bom potencial com relação a presença de aqüíferos fraturados. A segunda unidade apresenta relevo com grau de dissecação forte, solos com pequena espessura (inferiores a $5 \mathrm{~m}$ ) e lineamentos de pequeno a médio porte, o que a torna uma área com baixo potencial de ocorrência de aquiíferos fraturados.

O aqüífero fraturado na região é captado por 690 poços tubulares, sendo seus principais usos no abastecimento público urbano e rural (68\%), na indústria (25\%), no desenvolvimento de atividades agrícolas $(5 \%)$ e nas atividades recreativas $(2 \%)$.

$\mathrm{O}$ aqüífero fraturado possui características hidrodinâmicas que refletem sua forte anisotropia (Tabela 1). Os valores apresentados são médias gerais, sendo que para cada uma das regiões há variações nos parâmetros identificados (profundidade, entradas de água, nível estático, transmissividade, capacidade específica e vazões)

Com relação às características hidroquímicas, observou-se que as águas do aquífero fraturado estão distribuídas em três campos principais: águas bicarbonatadas cálcicas ou magnesianas $(80,1 \%)$, águas bicarbonatadas sódicas $(18,4 \%)$ e águas sulfatadas cálcicas ou magnesianas $(1,4 \%)$. Além disso, as águas apresentam boa qualidade para atividades industriais, agrícolas, recreativas ou abastecimento público. No entanto, um problema típico da região é a ocorrência de Fe e $\mathrm{Mn}$ em padrões acima do permitido, sendo sua origem relacionada com os processos de alteração das rochas vulcânicas. (Reginato, 2003 e Reginato \& Strieder, 2004).

CARACTERIZAÇÃO ESTRUTURAL As estruturas tectônicas na área de estudo são representadas por fraturas e zonas de fraturas que constituem conjuntos de lineamentos do tipo 2 (Strieder \& Amaro, 1997), associados à rede de drenagem e às estruturas morfológicas da região. A caracterização dessas estruturas foi realizada com base na análise de dados de campo e da interpretação de lineamentos extraídos de fotografias aéreas.

Análise Estrutural dos Dados de Campo A caracterização dessas zonas em campo, foi realizada com base no estudo geométrico e cinemático de estruturas (fraturas, zonas de fraturas, veios e diques) existentes em afloramentos (pedreiras e cortes de estrada, principalmente) ao longo de quatro perfis principais (Figura 2 e Tabela 2).

As principais estruturas existentes na área de estudo estão representadas por fraturas, zonas de fraturas, veios e diques. Salvo algumas exceções, os planos e as zonas de fraturas são verticais a sub-verticais e, quando preenchidos, apresentam mineralizações de zeolitas e sílica (quartzo microcristalino e calcedônia). Fraturas com preenchimento de zeolitas são mais comuns na seqüência de basaltos, enquanto os planos preenchidos por quartzo são mais comuns na seqüência de riodacitos e riolitos.

As fraturas apresentam orientação geral NE, sendo que a direção principal, identificada em todos os perfis é marcada pelos rumos $\mathrm{N} 70-80 \mathrm{E}$ e $\mathrm{N} 80-90 \mathrm{E}$. As direções secundárias são identificadas em alguns perfis, como a orientação N20 -30W no setor São Marcos (PCXSM) e N80 - 90W no setor Veranópolis (PBGV). Considerando as direções principais e secundárias desses setores, pode-se identificar um padrão ortogonal de fraturas.

As fraturas com preenchimento possuem orientações diversas, preferencialmente N70-80E, N00-10E, N10-20W, N60 - 90W. Além disso, há uma tendência para que os planos com preenchimento de zeolitas tenham uma orientação preferencial próxima a $\mathrm{N}-\mathrm{S}$, enquanto que os planos preenchidos por sílica teriam direções preferenciais para NE.

As zonas de fraturas apresentam orientações preferenciais 


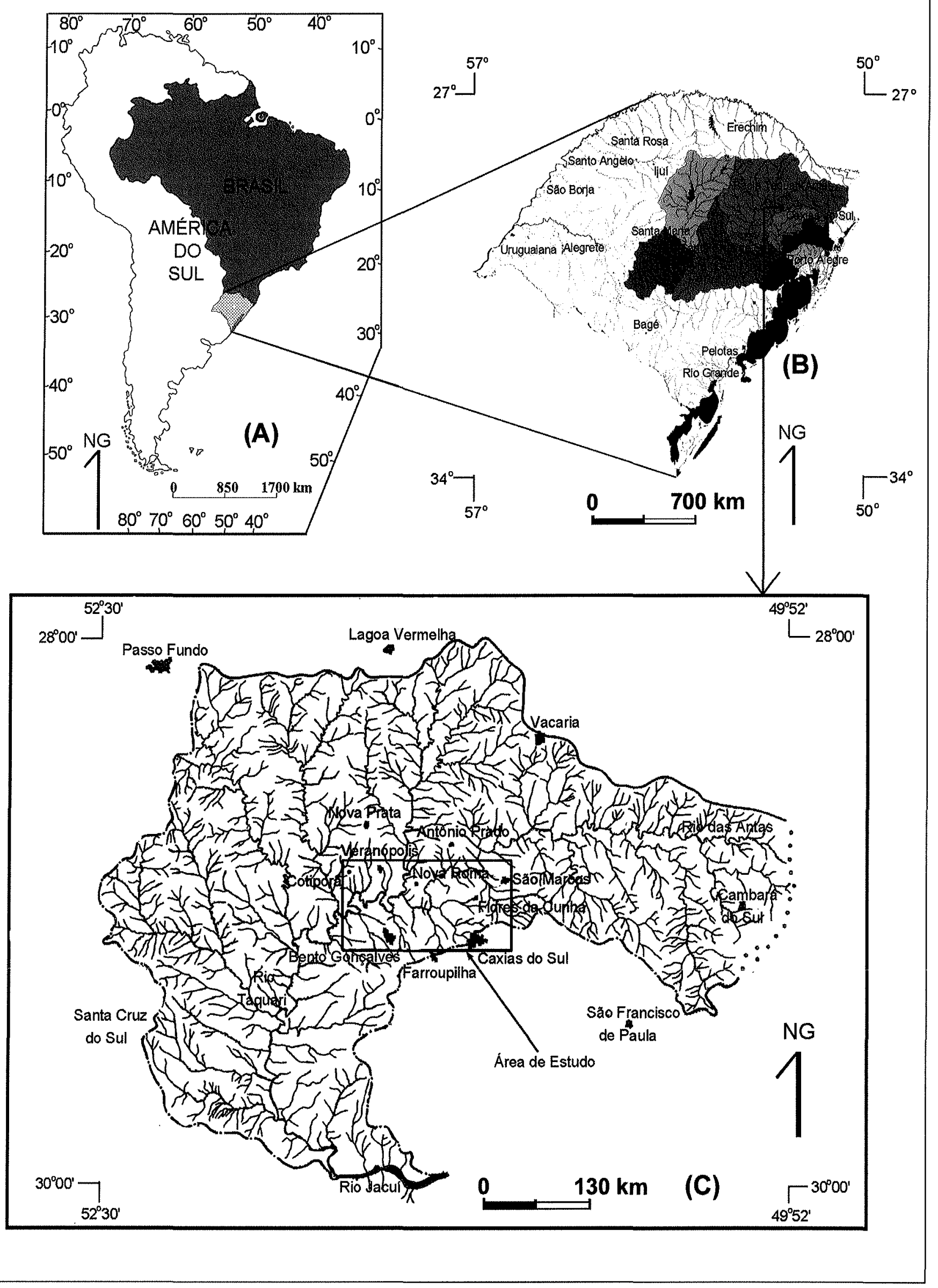

Figura 1 - Localização da área de estudo e relação com a bacia hidrográfica Taquari-Antas 
Tabela 1-Características hidrodinâmicas do aqüifero fraturado obtidas através da análise de dados hidrogeológicos de 238 poços tubulares.

\begin{tabular}{|c|c|c|c|}
\hline Características & \multicolumn{3}{|l|}{ Resultados } \\
\hline Profundidade Média dos Poços Tubulares & \multicolumn{3}{|l|}{$110 \mathrm{~m}$} \\
\hline Número de Entradas de Água & $1(43,5 \%)$ & $2(39,1 \%)$ & 3 ou $+(17,4 \%)$ \\
\hline Profundidade das Entradas de Água & \multicolumn{3}{|c|}{ Intervalo de 0 até 70 metros $(76 \%)$} \\
\hline Nivel Estático (NE) & 0 até $10 \mathrm{~m}(66,4 \%)$ & 10 a $20 \mathrm{~m}(16,4 \%)$ & $\begin{array}{l}\text { Acima de } 20 \mathrm{~m} \\
(17,2 \%)\end{array}$ \\
\hline Transmissividades (T) & $\begin{array}{l}\text { Média } \\
0,4931 \mathrm{~m}^{2} / \mathrm{h}\end{array}$ & $\begin{array}{l}\text { Mínima } \\
0,1325 \mathrm{~m}^{2} / \mathrm{h}\end{array}$ & $\begin{array}{l}\text { Máxima } \\
1,4578 \mathrm{~m}^{2} / \mathrm{h}\end{array}$ \\
\hline Capacidades Especificas (q) & $\begin{array}{l}\text { Média } \\
0,3954 \mathrm{~m}^{3} / \mathrm{h} / \mathrm{m}\end{array}$ & $\begin{array}{l}\text { Mínima } \\
0,106 \mathrm{~m}^{3} / \mathrm{h} / \mathrm{m}\end{array}$ & $\begin{array}{l}\text { Máxima } \\
1,1663 \mathrm{~m}^{3} / \mathrm{h} / \mathrm{m}\end{array}$ \\
\hline Vazões (Q) & $\begin{array}{l}>10 \mathrm{~m}^{3} / \mathrm{h} \\
72,1 \%\end{array}$ & $\begin{array}{l}10 \text { a } 20 \mathrm{~m}^{3} / \mathrm{h} \\
18,6 \%\end{array}$ & $\begin{array}{l}>20 \mathrm{~m}^{3} / \mathrm{h} \\
9,3 \%\end{array}$ \\
\hline
\end{tabular}

N70 - 90E, N00 - 10E e N70 - 90W. Essa geometria é semelhante àquela apresentada pelos planos de fraturas e pelos planos com preenchimento, o que evidencia a presença de um sistema aproximadamente ortogonal.

Os veios são caracterizados por planos que formam conjugados e ramificações. A orientação preferencial é para N20 $-60 \mathrm{~W}$, que pode estar associada a planos de cisalhamento. Por outro lado, há uma orientação secundária, próxima a Norte-Sul, que corresponde a planos considerados como alimentadores de geodos.

Os diques correspondem a estruturas de dimensões variadas, sendo centimétricos $(1$ a $3 \mathrm{~cm})$, preenchidos por arenitos nas direções $\mathrm{N} 20-30 \mathrm{E}$ e, decimétricos $(20$ a $30 \mathrm{~cm})$, preenchidos por diabásios, nas direções N50 - 60E.

A análise geométrica revelou um padrão aproximadamente ortogonal com estruturas de orientação próxima a Norte-Sul e Leste-Oeste. As estruturas com orientações diferentes desse padrão, provavelmente correspondem a planos de cisalhamento, onde se alojaram os veios e diques.

A análise cinemática foi realizada a partir de fraturas que continham indicadores de movimento (estrias). A identificação dos campos paleotensionais foi realizada pelo método dos Diedros Retângulos de Angelier \& Mechler (1977), que revelou dois campos tensionais principais (Tabela 3, Figura 3 e 4). $\mathrm{O}$ primeiro campo tensional está registrado em quatro conjuntos de afforamentos e se caracteriza por um campo horizontal 1 de orientação $082^{\circ}$ e campo horizontal 3 de orientação $352^{\circ}$. Para esse campo tensional, as estruturas paralelas e sub-paralelas a ao campo $1\left(262^{\circ}\right)$ são denominadas de fraturas trativas (T), enquanto as estruturas oblíquas a essa direção seriam fraturas híbridas e de cisalhamento, dependendo do ângulo diedro com as fraturas T. As fraturas trativas, em geral, apresentam preenchimento, enquanto as oblíquas podem estar preenchidas ou não. O preenchimento das fraturas depende de dois fatores: i) existência de espaço de dilatância e ii) circulação de fluidos com carga iônica, condições cumpridas para as fratura T. No caso das fraturas oblíquas, a existência de dilatância depende da formação de ramificações transtrativas. Esse parece ter sido o caso, pois boa parte das fraturas oblíquas com orientação NE correspondem a planos onde estão alojados os veios e diques.

O segundo campo tensional foi caracterizado a partir dos dados do conjunto denominado de Pedreira Codeca 1 , onde foi definido campo 1 horizontal $174^{\circ}$ e campo 3 horizontal $264^{\circ}$. Nesse campo, as fraturas trativas são as estruturas paralelas e sub-paralelas ao campo 1 e estão comumente preenchidas. As estruturas oblíquas entre os eixos campo 1 e campo 3, corres- pondem a fraturas híbridas e de cisalhamento. Em parte dessas estruturas, há o alojamento de veios.

Os dois campos tensionais são ortogonais, o que corrobora os dados obtidos com a análise geométrica. Esse padrão ortogonal de esforço também foi identificado por Heeman \& Strieder (1999) para a Formação Serra Geral na região de Salto do Jacuí (RS).

Análise Estrutural dos Lineamentos A extração dos lineamentos foi realizada com base na interpretação de fotografias aéreas na escala 1:60.000 (Reginato \& Strieder, 2001). Para a região nordeste foram identificados 4154 estruturas do tipo 2 , separadas em quatro grupos principais: $\mathrm{N}-\mathrm{S}, \mathrm{NE}, \mathrm{L}-\mathrm{W}$ e NW (Figura 5) e tratadas através de técnicas de estatística vetorial (Tabela 4).

Os comprimentos médios dos vetores nos quatro grupos são próximos e variam entre 855 a 892 metros. Somente o grupo dos lineamentos leste-oeste apresenta um comprimento um pouco superior, na faixa dos 930 metros. Os azimutes médios de cada grupo estão associados às orientações preferenciais e secundárias identificadas em campo. Por outro lado, ao analisar as diferentes regiões correspondentes aos perfis geológicos, observase variações mais significativas com relação aos comprimentos médios dos vetores e menores nos azimutes médios.

O SISTEMA ESTRUTURAL E OS AQÜÍFEROS FRATURADOS A determinação da relação entre o sistema estrutural e os aqüíferos fraturados foi realizada com base em técnicas de integração de dados utilizando o programa SPRING (Reginato, 2003; Reginato \& Strieder, 1999). As técnicas utilizadas corresponderam a rotinas de processamento denominadas de: medida de classes, tabulação cruzada e a ferramenta de análise e suporte a decisão ("Processo Analítico Hierárquico - AHP).

Para a integração de dados foram gerados planos de informações, sendo quatro correspondentes a cada um dos grupos de lineamentos identificados na etapa de análise estrutural (PI's denominados de fraturas) e um referente ao cadastro de poços tubulares (total de 407 poços que formavam o PI cadastro). Além disso, foi gerado um plano de informação referente ao cruzamento de lineamentos (PI cruzamento).

$\mathrm{Na}$ integração tabulação cruzada entre os PI's fratura e cadastro, observou-se uma associação de poços tubulares praticamente igual para os grupos de lineamentos nordeste e noroeste. Para o intervalo de vazões entre 10 e $20 \mathrm{~m}^{3 / \mathrm{h}}$, há uma associação um pouco maior de poços tubulares com o grupo de lineamentos nordeste. Por outro lado, observa-se que a ocorrência de vazões 


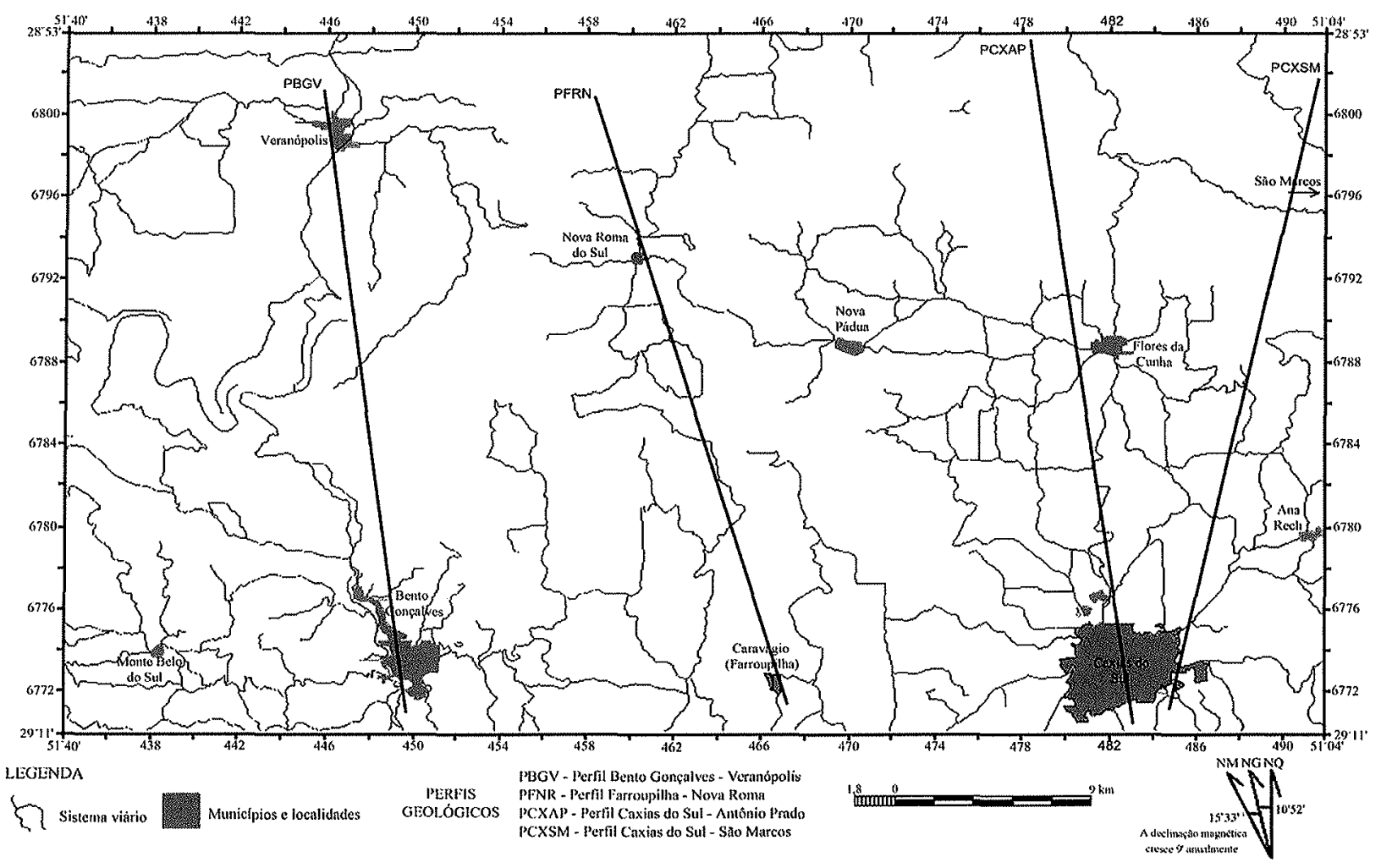

Figura 2 - Localização dos perfis geológicos realizados com o levantamento estrutural de campo

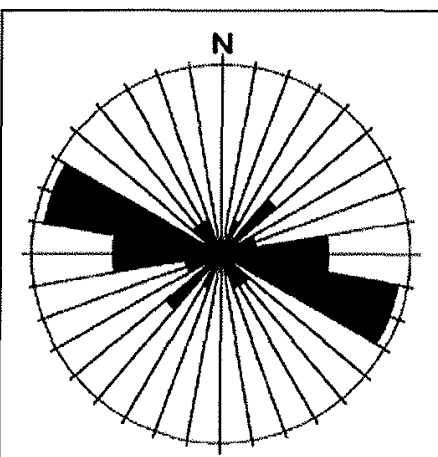

Numero de Medidas $=24$ planos

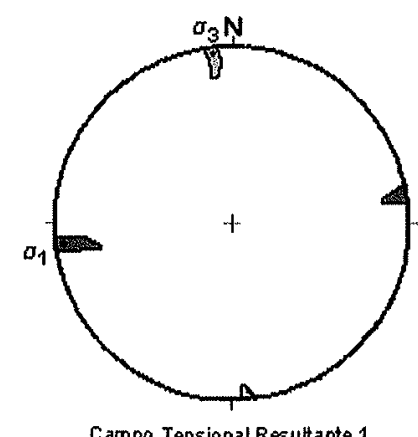

Figura 3 - Histograma de freqüência das medidas utilizadas $e$ resultado da análise cinemática do campo tensional resultante 1

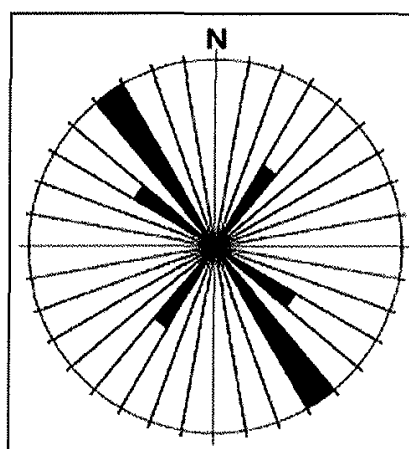

Número de medidas $=4$ planos

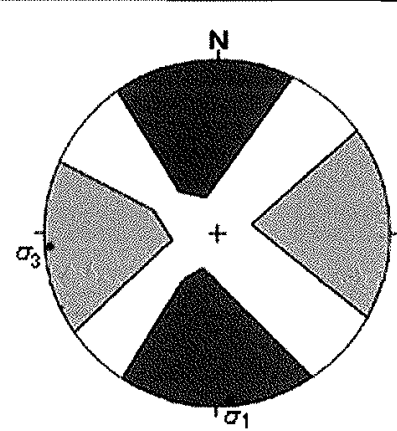

Campce Tensionas. Pedreira Codeoa 1
Figura 4 - Histograma de freqüencia das medidas utilizadas e resultado da análise cinemática do campo tensional resultante 2. acima de $20 \mathrm{~m}^{3 / \mathrm{h}}$ possui uma relação maior com lineamentos noroeste. A análise dos lineamentos do grupo leste-oeste e norte-sul mostra uma ocorrência menor de poços tubulares nessas estruturas. No entanto, quando são comparados diferentes intervalos de vazões, torna-se evidente uma maior correlação com os lineamentos norte-sul do que com os leste-oeste.

$\mathrm{Na}$ tabulação cruzada entre os PI's cruzamento e cadastro, observou-se que há uma coincidência pequena de poços tubulares com a intersecção de lineamentos $(8,1 \%)$. Isso indica não ser esse o principal fator a ser seguido na hora da locação de poços tubulares profundos. No entanto, pode-se evidenciar uma associação entre poços tubulares com vazões entre 0 e $5 \mathrm{~m}^{3 / 1} \mathrm{e}$ acima de $10 \mathrm{~m}^{3 / 1}$ com os cruzamentos de fraturas. Da mesma forma, identificou-se uma correlação entre poços tubulares nulos e o cruzamento de lineamentos.

Como ficou evidenciada a existência de comportamentos diferenciados dos lineamentos que compõem os quatro grupos de estruturas, foi realizada uma análise entre a localização de cada um dos poços tubulares (produtivos e nulos) e as orientações das estruturas, por meio de interpretação visual e técnicas de tabulação cruzada (Tabela 5). Pode-se ressaltar que:

- os lineamentos noroeste (grupo 3) os rumos N30 - 40W, $\mathrm{N} 50$ - 60W e N60 - 70W estão associados a poços tubulares que apresentam vazões acima de $20 \mathrm{~m}^{3 / \mathrm{h}}$;

- os lineamentos nordeste (grupo 2) as orientações N20 $-30 \mathrm{E}$ e N40 - 50E possuem maior correlação com poços tubulares que têm vazões maiores que $20 \mathrm{~m}^{3 / \mathrm{h}}$;

- os lineamentos norte-sul (grupo1) as direções N10 -14E apresentam maior relação com poços tubulares que possuem vazões acima de $20 \mathrm{~m}^{3 / 1}$; os lineamentos leste-oeste (grupo 4) o rumo $\mathrm{N} 80-90 \mathrm{~W}$ possui maior ocorrência de poços tubulares 
Tabela 2 - Resumo da análise geométrica das estruturas identificadas nos perfis.

\begin{tabular}{|c|c|c|c|c|}
\hline Perfil & Setores & Tipo de Estrutura & $\begin{array}{l}\text { Orientação } \\
\text { Quadrante }\end{array}$ & Direção principal \\
\hline \multirow{5}{*}{$\begin{array}{l}\text { Caxias do Sul - São } \\
\text { Marcos (PCXSM) }\end{array}$} & \multirow{5}{*}{$\begin{array}{l}\text { Caxias do Sul } \\
\text { e } \\
\text { São Marcos }\end{array}$} & Fraturas & NE e NW & $\begin{array}{l}\mathrm{N} 70-80 \mathrm{E} \\
\mathrm{N} 20-30 \mathrm{~W}\end{array}$ \\
\hline & & $\begin{array}{l}\text { Fraturas com } \\
\text { Preenchimento }\end{array}$ & $\mathrm{N}-\mathrm{S}$ e NE & $\begin{array}{l}\text { N70-80E } \\
\text { No }-10 \mathrm{E} \\
\text { NO }-20 \mathrm{~W} \\
\text { N70-80W }\end{array}$ \\
\hline & & \begin{tabular}{|l} 
Zonas de Fraturas \\
\end{tabular} & $\mathrm{N}-\mathrm{S}$ e NE & $\begin{array}{l}\text { N60-90E } \\
\text { No0- } 10 E\end{array}$ \\
\hline & & Veios & NW & $\mathrm{N} 20-60 \mathrm{~W}$ \\
\hline & & Diques & NE & $\mathrm{N} 20-70 \mathrm{E}$ \\
\hline \multirow{3}{*}{$\begin{array}{l}\text { Caxias do Sul - Antônio } \\
\text { Prado (PCXAP) }\end{array}$} & & Fraturas & $\mathrm{NE}$ & N80-90E \\
\hline & & $\begin{array}{l}\text { Fraturas com } \\
\text { preenchimento }\end{array}$ & $\mathrm{N}-\mathrm{S}$ & NOO- $10 \mathrm{E}$ \\
\hline & & Zonas de Fraturas & $\mathrm{NE}$ & $\mathrm{N} 80-90 \mathrm{E}$ \\
\hline \multirow{4}{*}{$\begin{array}{l}\text { Farroupilha - Nova } \\
\text { Roma (PFNR) }\end{array}$} & \multirow{4}{*}{$\begin{array}{l}\text { Nova Roma } \\
\text { e } \\
\text { Farroupilha }\end{array}$} & Fraturas & $\mathrm{NE}$ & $\mathrm{N} 70-90 \mathrm{E}$ \\
\hline & & $\begin{array}{l}\text { Fraturas com } \\
\text { preenchimento }\end{array}$ & $\begin{array}{l}\mathrm{N}-\mathrm{S} \\
\mathrm{NE}\end{array}$ & $\begin{array}{l}\text { N00-10E } \\
\text { N00-10W } \\
\text { N80-90E }\end{array}$ \\
\hline & & Fraturas Ortogonais & $\begin{array}{l}\mathrm{NE} \\
\mathrm{NW}\end{array}$ & $\begin{array}{l}\text { N00-10E } \\
\text { N80-90E } \\
\text { N70-90W }\end{array}$ \\
\hline & & Zonas de Fraturas & $\mathrm{NE}$ & $\mathrm{N} 60-80 \mathrm{E}$ \\
\hline \multirow{6}{*}{$\begin{array}{l}\text { Bento Gonçalves - } \\
\text { Veranópolis (PBGV) }\end{array}$} & \multirow{6}{*}{$\begin{array}{l}\text { Bento Gonçalves } \\
\text { e } \\
\text { Veranópolis }\end{array}$} & Fraturas & $\mathrm{NE}$ & $\begin{array}{l}\mathrm{N} 70-80 \mathrm{E} \\
\mathrm{N} 80-90 \mathrm{~W}\end{array}$ \\
\hline & & $\begin{array}{l}\text { Fraturas com } \\
\text { preenchimento }\end{array}$ & NW & $\begin{array}{l}\mathrm{N} 60-70 \mathrm{~W} \\
\mathrm{~N} 80-90 \mathrm{~W}\end{array}$ \\
\hline & & Fraturas Ortogonais & $\begin{array}{l}\mathrm{NE} \\
\mathrm{NW}\end{array}$ & $\begin{array}{l}\text { N05W - N85E } \\
\text { N42E - N48W }\end{array}$ \\
\hline & & Zonas de Fraturas & NW & N70-90W \\
\hline & & Veios & NW & $\begin{array}{l}\text { N30-60W } \\
\text { N00-10W }\end{array}$ \\
\hline & & Diques & NE & $\begin{array}{l}\mathrm{N} 20-30 \mathrm{E} \\
\mathrm{N} 40-50 \mathrm{E}\end{array}$ \\
\hline
\end{tabular}

com vazões acima de $20 \mathrm{~m}^{3 / 1}$.A observação da correlação entre os poços tubulares nulos com a orientação dos lineamentos que pertencem aos diferentes grupos mostra o seguinte: $\cdot 20,54 \%$ dos poços tubulares nulos não possuem relação com nenhum tipo de estrutura; $36,99 \%$ dos poços tubulares nulos apresentam rela- ção com os lineamentos do grupo 2 (nordeste), com orientações principais em N30 - 40E e N50 - 60E;・17,81\% dos poços tubulares nulos estão associados a lineamentos noroeste (grupo 3), com orientação principal N40 - 50W;・ $13,7 \%$ dos poços tubulares nulos estão associados a estruturas do grupo 1 (norte-sul), 
Tabela 3 - Orientação dos campos tensionais identificados na análise cinemática e relação dos dois campos resultantes.

\begin{tabular}{|l|l|l|l|}
\hline Conjuntos de Estudo & $\begin{array}{l}\text { Campos Tensionais } \\
\text { Identificados }\end{array}$ & $\begin{array}{l}\text { Campo Tensional } \\
\text { Resultante 1 }\end{array}$ & $\begin{array}{l}\text { Campo Tensional } \\
\text { Resultante 2 }\end{array}$ \\
\hline Pedreira Guerra & $\sigma_{1}=10^{\circ} 074^{\circ}$ & \\
Perfil Caxias do Sul - São & $\sigma_{2}=80^{\circ} 256^{\circ}$ & & \\
Marcos & $\sigma_{3}=03^{\circ} 346^{\circ}$ & & \\
\cline { 1 - 2 } Afloramento Tega & $\sigma_{1}=15^{\circ} 073^{\circ}$ & & \\
Perfil Caxias do Sul - Antônio & $\sigma_{2}=72^{\circ} 270^{\circ}$ & & \\
Prado & $\sigma_{3}=04^{\circ} 165^{\circ}$ & $\sigma_{1}=07^{\circ} 262^{\circ}$ & \\
\cline { 1 - 2 } Afloramento Veranópolis & $\sigma_{1}=10^{\circ} 068^{\circ}$ & $\sigma_{2}=80^{\circ} 126^{\circ}$ & \\
Perfil Bento Gonçalves- & $\sigma_{2}=80^{\circ} 248^{\circ}$ & $\sigma_{3}=04^{\circ} 352^{\circ}$ & \\
Veranópolis & $\sigma_{3}=02^{\circ} 158^{\circ}$ & & \\
\cline { 1 - 2 } Pedreira Codeca 2 & $\sigma_{1}=03^{\circ} 263^{\circ}$ & & $\sigma_{1}=01^{\circ} 174^{\circ}$ \\
Perfil Caxias do Sul - Antônio & $\sigma_{2}=88^{\circ} 092^{\circ}$ & & $\sigma_{2}=86^{\circ} 084^{\circ}$ \\
Prado & $\sigma_{3}=02^{\circ} 357^{\circ}$ & & $\sigma_{3}=04^{\circ} 264^{\circ}$ \\
\hline Pedreira Codeca 1 & $\sigma_{1}=01^{\circ} 174^{\circ}$ & & \\
Perfil Caxias do Sul - Antônio & $\sigma_{2}=86^{\circ} 084^{\circ}$ & & \\
Prado & $\sigma_{3}=04^{\circ} 264^{\circ}$ & & \\
\hline
\end{tabular}

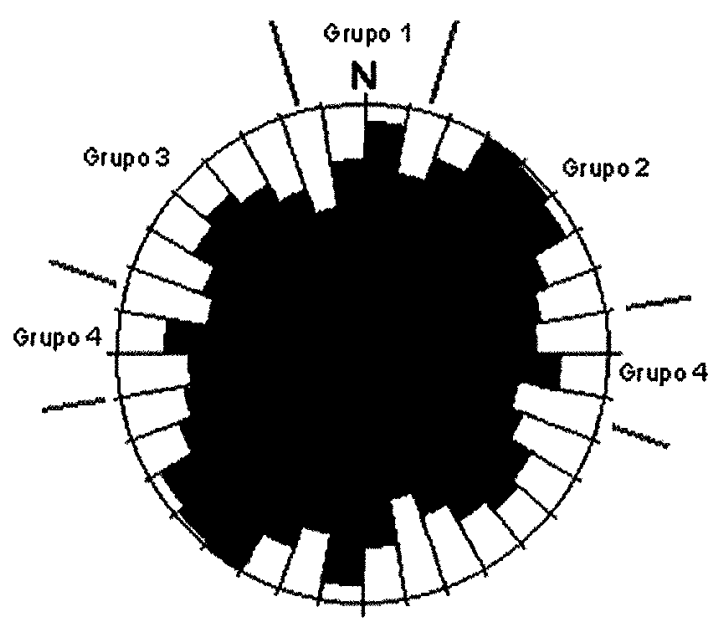

Figura 5 - Histogragrama de freqüência circular com os 4154 lineamentos obtidos na fotointerpretação.

com rumo principal N00 - 10E; $\cdot 10,96 \%$ dos poços tubulares nulos possuem relação com estruturas do grupo 4 (leste-oeste), com principal orientação marcada pelo rumo N75 - 80W.

CONCLUSÕES Os aqüíferos fraturados possuem grande importância na região nordeste do estado do Rio Grande do Sul, visto que correspondem a fontes de recursos hídricos utilizados para o desenvolvimento de diversas atividades (abastecimento, indústria, agropecuária, entre outros usos).

Esses aquífferos estão localizados na seqüência de rochas vulcânicas (ácidas e básicas) da Formação Serra Geral sendo condicionados pelo sistema estrutural existente na região. $\mathrm{Na}$ Formação Serra Geral o arcabouço estrutural é caracterizado por lineamentos do tipo 2 , representadas principalmente por fraturas e zonas de fraturas e pela atuação de dois campos tensionais (padrão ortogonal com orientação próxima a Norte-Sul e Leste-Oeste). O resultado foi a formação de fraturas trativas, paralelas e sub-paralelas ao eixo de tensão principal do campo
1 que, em geral apresentam preenchimento, e fraturas híbridas e de cisalhamento (oblíquas entre os eixos de compressão e tração) que, podem ou não estar preenchidas.Com a integração de dados pode-se determinar a relação existente entre o sistema estrutural e os aqüíferos fraturados. Observou-se uma forte correlação entre os lineamentos e a ocorrência de poços tubulares produtivos, sendo que as estruturas nordeste e noroeste correspondem às principais. $\mathrm{O}$ intervalo de vazão $10 \mathrm{a} 20 \mathrm{~m}^{3 / \mathrm{h}}$ possui maior associação com os lineamentos de orientação nordeste, enquanto que vazões acima de $20 \mathrm{~m}^{3 / \mathrm{h}}$ possuem maior relação com lineamentos de orientação noroeste. Por outro lado, foi identificada uma correlação entre poços tubulares nulos e os diferentes grupos de estruturas, principalmente o grupo nordeste. Isso evidencia que as estruturas que constituem os diferentes grupos apresentam comportamentos diferenciados com relação a ocorrência de água subterrânea.A análise das orientações de cada grupo de lineamentos e a sua correlação com poços tubulares produtivos mostra que, para os lineamentos noroeste, as orientações N30 - 60W são as principais. Para as estruturas nordeste as orientações $\mathrm{N} 20-30 \mathrm{E}, \mathrm{N} 40-50 \mathrm{E}$ e N70 - 80E são as que possuem maior associação a aqüíferos fraturados. No caso dos lineamentos norte-sul e leste-oeste as direções N00 - 14E e N80 - 90W apresentam maior ocorrência de poços produtivos. Por outro lado, foi identificada uma associação entre poços nulos com diferentes grupos de lineamentos. Nesse caso a maior ocorrência está associada às estruturas nordeste, sendo que os rumos N30 - 40E e N50 - 60E são os principais. Para outros grupos de estruturas, foi observada uma menor correlação sendo que para os lineamentos noroeste a orientação principal é de $\mathrm{N} 40-50 \mathrm{~W}$, para os norte-sul é N00-10E e para os leste-oeste é N75-80W.

A análise do sistema estrutural e sua relação com os aqüíferos fraturados da Formação Serra Geral permite determinar que o principal condicionante corresponde ao sistema estrutural. Sendo assim, nos processos de prospecção de água subterrânea, nessas regiões, devem ser realizados estudos visando a caracterização estrutural da área, envolvendo tanto interpretação de lineamentos quanto levantamentos estruturais de campo para que as chances de ocorrência de poços produtivos sejam aumentadas. 
Tabela 4 - Distribuição dos lineamentos identificados na interpretação de fotografias aéreas e sua distribuição nos quatro grupos.

\begin{tabular}{|l|l|l|l|l|}
\hline Grupo & Intervalo - Range & $N^{\circ}$ de Lineamentos & Orientação Média & Comprimento Médio \\
\hline 1 & N00-14E e N00-14W & 663 & N00-10E e N00-10W & $630,463-990,714 \mathrm{~m}$ \\
\hline 2 & N15-84E & 1751 & N30-60E & $675,732-979,017 \mathrm{~m}$ \\
\hline 3 & N15-75W & 1316 & N40-50W & $642,225-974,951 \mathrm{~m}$ \\
\hline 4 & N85-90E e N75-90W & 424 & N80-90W & $741,818-1082,154 \mathrm{~m}$ \\
\hline
\end{tabular}

Tabela 5-Correlação entre poços tubulares produtivos (diferentes vazões) e as orientações dos diferentes grupos de lineamentos.

\begin{tabular}{|c|c|c|c|c|c|c|c|c|}
\hline \multicolumn{9}{|c|}{ Grupo 1 - Lineamentos de orientação N-S } \\
\hline Range $^{\circ}$ & \multicolumn{2}{|l|}{$\mathrm{NO}-10 \mathrm{E}$} & \multicolumn{2}{|c|}{$\mathrm{N} 10-14 \mathrm{E}$} & \multicolumn{2}{|c|}{$\mathrm{N} 10-14 \mathrm{~W}$} & \multicolumn{2}{|c|}{ N00 - 10W } \\
\hline$\%$ & \multicolumn{2}{|l|}{24,39} & \multicolumn{2}{|c|}{24,39} & \multicolumn{2}{|c|}{2,44} & \multicolumn{2}{|c|}{48,78} \\
\hline \multicolumn{9}{|c|}{ Grupo 2 - Lineamentos de orientação NE } \\
\hline Range $^{\circ}$ & 15 a 20 & 20 a 30 & 30 a 40 & 40 a 50 & 50 a 60 & 60 a 70 & 70 a 80 & 80 a 84 \\
\hline$\%$ & 2,41 & 22,58 & 12,90 & 24,20 & $8,87 \%$ & $5,65 \%$ & $18,55 \%$ & $4,84 \%$ \\
\hline \multicolumn{9}{|c|}{ Grupo 3 - Lineamentos de orientação NW } \\
\hline Range $^{\circ}$ & 15 a 20 & 20 a 30 & 30 a 40 & 40 a 50 & 50 a 60 & 60 a 70 & 70 a 75 & \\
\hline$\%$ & 3,75 & 15,04 & 18,8 & 18,05 & 22,56 & 12,78 & 9,02 & \\
\hline \multicolumn{9}{|c|}{ Grupo 4 - Limeamentos de orientação E-O } \\
\hline Range $^{\circ}$ & \multicolumn{2}{|c|}{$\mathrm{N} 85-90 \mathrm{E}$} & \multicolumn{2}{|c|}{$\mathrm{N} 80-90 \mathrm{~W}$} & \multicolumn{2}{|c|}{ N75-80W } & & \\
\hline$\%$ & \multicolumn{2}{|l|}{$24,39 \%$} & \multicolumn{2}{|c|}{$51,22 \%$} & \multicolumn{2}{|c|}{$24,39 \%$} & & \\
\hline
\end{tabular}

\section{Referências}

ANGELIER, J. \& MECHLER, P. 1977. Sur une methode graphique de recherché des contraintes principales egalment utilizable en tectonique et sen seismologie: la methode des diedres droits. Bull. Soc. Geól. France., v.19, p. 1309-1318.

CPRM. 1998. Mapeamento geológico integrado da bacia hidrográfica do Guaiba: carta geológica: FolhaSH.22-V-B - Passo Fundo. Companhia de Pesquisas de Recursos Minerais. . Porto Alegre (Brasil), 1 mapa color. Escala 1:250.000. Material cartográfico.

CPRM. 1998. Mapeamento geológico integrado da bacia hidrográfica do Guaiba: carta geológica: FolhaSH.22-V-D - Caxias do Sul. Companhia de Pesquisas de Recursos Minerais. . Porto Alegre (Brasil), 1 mapa color. Escala 1:250.000. Material cartográfico.

HAUSMAN, A. 1995. Províncias Hidrogeológicas do Estado do Rio Grande do Sul, RS. Estudos Tecnológicos: Acta Geológica Leopoldensia, Série Mapas. $N^{\circ}$ 2. P-1-127.

HEEMANN, R. \& STRIEDER, A. 1999. Análise geométrica de estruturas da sucessão vulcânica associada aos depósitos de ágata do distrito mineiro de Salto do Jacuí (RS). In: VII Simpósio Nacional De Estudos Tectônicos. Bahia. SBG/BA.ABGP. Sessão 6 p. 1416.

LISBOA, N.A. 1993. Compartimentação Hidrogeológica e Diferenciação Hidrogeoquímica em Aqüíferos do Extremo Sul do Planalto Meridional do Rio Grande do Sul. In: Simpósio Brasileiro De Recursos Hídricos 10, Gramado/RS, 1993. Anais. p. 539-548.

LISBOA, N.A. 1996. Fácies, estratificações hidrogeoquímicas e seus controladores geológicos, em unidades hidrogeológicas do siste- ma aqüífero Serra Geral, na bacia do Paraná, Rio Grande do Sul. Porto Alegre, Tese de doutorado em Geociências, Instituto de Geociências, Programa de Pós-Graduação em Geociências. Universidade Federal do Rio Grande do Sul. 135p. il. (Inédito).

MAGNA., 1997. Avaliação Quali-Quantitativa das Disponibilidades e Demandas de Água na Bacia Hidrográfica do Sistema Taquari-Antas. Magna Engenharia Ltda. Departamento dos Recursos Hídricos e Saneamento. Porto Alegre. Relatório Final

RADAM/BRASIL. 1986. Folha SH.22 Porto Alegre e parte das Folhas SH.21 Uruguaiana e SI.22 Lagoa Mirim: Geologia, Geomorfologia, Pedologia, Vegetação, Uso Potencial da Terra. 1986. Rio de Janeiro: IBGE 796p. (Levantamento de Recursos Naturais, v..33).

REGINATO, P.A.R. 2003. Integração de Dados Geológicos para Prospecção de Aqüiferos Fraturados em Trecho da Bacia Hidrográfica Taquari-Antas (RS). Tese de Doutorado em Engenharia. Escola de Engenharia, Programa de Pós-Graduação em Engenharia de Minas, Metalúrgica e dos Materiais. Universidade Federal do Rio Grande do Sul. 254p.

REGINATO, P.A.R. \& STRIEDER, A. J. 1999. Integração De Dados Na Prospecção De Aqǘf́eros Fraturados Em Parte Da Bacia Hidrográfica Taquari-Antas (Rio Grande Do Sul). In: Congresso E Feira Para Usuários De Geoprocessamento Da América Latina, V (GISBRASIL 99), Salvador, Bahia. Anais CD-ROM.

REGINATO, P.A.R. \& STRIEDER, A. J. 2001. Extração de Lineamentos visando a prospecção de aqüíferos fraturados - fotografias aéreas ou imagens de satélite? In: XX Congresso Brasileiro De Cartografia. XXCBC. Porto Alegre- Anais. CdRoom. 
REGINATO, P.A.R.; STRIEDER, A.J. 2004. Caracterização Hidrogeológica e Potencialidades dos Aqüíferos Fraturados da Formação Serra Geral na Região Nordeste do Estado do Rio Grande do Sul. In: XIII Congresso Brasileiro de Águas Subterrâneas, Cuiabá, Anais (CdRoom)

REGINATO, P.A.R.; STRIEDER, A.J. 2004 Caracterização Hidroqúimica Dos Aquiferos Fraturados Da Formação Serra Geral Na Região Nordeste Do Estado Do Rio Grande Do Sul In: XIII Congresso Brasileiro De Águas Subterrâneas, Cuiabá, Anais (CdRoom).

ROISENBERG, A. 1990. Petrologia e Geoquímica do Vulcanismo Ácido Mesozóico da Provincia Meridional da Bacia do Paraná. Porto Alegre, Tese de doutorado em Geociências, Instituto de Geociências, Universidade Federal do Rio Grande do Sul. (Inédito).
STRIEDER, A.J. \& AMARO, V.E. 1997. Estruturas de Lineamentos Extraídos de Imagens de Sensores Remotos. EGATEA. Revista da Escola de Engenharia, Porto Alegre. v. 25, $\mathrm{n}^{\circ} 4$, julho-agosto de 1997. p.109-117

WHITE, I.C. 1908. Relatório Final Comissão de Estudos das Minas de Carvão de Pedra do Brasil. Rio de Janeiro. v. 1, 300p.

ZALAN, P.V.; WOLFF, S.; CONCEIÇÃO, J.C.J., MARQUES, A.; ASTOLFI, M.A.M.; VIEIRA, I.S.; APPI, V.T.; ZANOTTO, O.A. 1990. Bacia do Paraná. In: RAJA GABAGLIA, G.P. \& MILANI, E.J. (Coords.) Origem e Evolução das Bacias Sedimentares. Rio de Janeiro:PETROBRÁS, p.135-168.

Manuscrito A-1593

Revisão aceita em 14 de junho de 2006 
